\title{
Visceral pleural invasion predict a poor survival among lung adenocarcinoma patients with tumor size $\leq 3 \mathrm{~cm}$
}

\author{
Tianxiang Chen ${ }^{1, *}$, Jizhuang Luo ${ }^{1, *}$, Rui Wang ${ }^{1}$, Haiyong Gu${ }^{1}, \mathbf{Y u} \mathbf{G u}^{2}$, Qingyuan \\ Huang $^{1}$, Yiyang Wang ${ }^{1}$, Jiajie Zheng ${ }^{1}$, Chang Gu ${ }^{1}$, Xufeng Pan ${ }^{1}$, Jun Yang ${ }^{1}$, Yunhai \\ Yang ${ }^{1}$ and Heng Zhao ${ }^{1}$ \\ ${ }^{1}$ Department of Thoracic Surgery, Shanghai Chest Hospital, Shanghai Jiao Tong University, Shanghai, China \\ 2 Department of Radiation Oncology, Shanghai Cancer Hospital, Fudan University, Shanghai, China \\ * These authors have contributed equally to this work \\ Correspondence to: Yunhai Yang, email: docyyh@163.com
}

Heng Zhao, email: h_zhao28@163.com

Keywords: invasive lung adenocarcinoma, non-small cell lung cancer, VPI, stage I

Received: February 08, $2017 \quad$ Accepted: March 14, $2017 \quad$ Published: March 22, 2017

Copyright: Chen et al. This is an open-access article distributed under the terms of the Creative Commons Attribution License 3.0 (CC BY 3.0), which permits unrestricted use, distribution, and reproduction in any medium, provided the original author and source are credited.

\section{ABSTRACT}

Introduction: The impact of visceral pleural invasion (VPI) on survival remains controversial for patients with early stage non-small cell lung cancer (NSCLC). This study investigated the survival status of VPI among patients with lymph nodenegative lung invasive adenocarcinoma smaller than $3 \mathrm{~cm}$.

Methods: We retrospectively reviewed 2537 consecutive patients with pathologic stage I lung invasive adenocarcinoma. All patients had received lobectomy and system lymph nodes resection.

Patients were classified into $\mathbf{4}$ groups according to tumor size and visceral pleural invasion status. Disease-free survival (DFS) and overall survival (OS) were analyzed to evaluate survival difference between these groups.

Results: 548 patients with VPI while 1989 patients without VPI were included in this study. For patients with tumor size $\leq \mathbf{c m}$, patients with VPI had significant worse DFS (HR,4.85; 95\% CI, 2.98-7.91; $p=.000)$ and OS(HR,3.52; 95\% CI, 1.59-7.78; $p$ $=.002$ ) compared with non-VPI group. For patients with tumor size between $2-3 \mathrm{~cm}$, patients with VPI had significant worse DFS (HR, 1.72; 95\% CI, 1.16-2.55; $p=.006$ ) but no significant OS (HR, 1.31; 95\% CI, 0.76-2.24; $p=.330)$ compared with non-VPI group. For patients with VPI, there were no survival difference between tumor size $2-3 \mathrm{~cm}$ group and $\leq 2 \mathrm{~cm}$ group for both DFS(HR,1.02; 95\% CI, 0.65-1.61; $p=.939)$ and OS(HR,1.45; 95\% CI, 0.71-2.97; $p=.315)$.

Conclusions: VPI could predict a poor survival even for node-negative invasive lung adenocarcinoma patients with tumor size less than $3 \mathrm{~cm}$.

\section{INTRODUCTION}

Lung cancer is one of the primary causes of cancerrelated death in both men and women worldwide. [1] More and more early stage non-small cell lung cancer (NSCLC) have been detected recently due to rapid developments in imaging technology and widely application of thin-section computed tomography (CT) for screening high-risk patients [2,3]. Adenocarcinoma is the most common type of NSCLC [4]. Despite early stage lung adenocarcinoma patients who had received curative-intent lobectomy, the post-surgical survival varies greatly. Visceral pleural invasion of lung cancer has been recognized as an adverse prognosis indicator for decades [5]. Previous studies indicated that VPI is an independent poor prognostic predictor regardless tumor size or $\mathrm{N}$ status. [6] However, there is no consensus on the impact of VPI on survival among patients with tumor size less than $3 \mathrm{~cm}$, especially less than $2 \mathrm{~cm} \mathrm{[7].} \mathrm{In} \mathrm{the} \mathrm{7th} \mathrm{edition} \mathrm{of} \mathrm{the} \mathrm{tumor,} \mathrm{node,}$ metastasis (TNM) classification system of lung cancer, 
pathological $\mathrm{T}$ stage upstages from $\mathrm{T} 1 \mathrm{a}$ to $\mathrm{T} 1 \mathrm{~b}$ in the specimen of tumor size $\leq 3 \mathrm{~cm}$ with VPI $[8,9]$. Some recent researches demonstrated that for NSCLC patients with tumor size $\leq 3 \mathrm{~cm}$, there were no significant survival difference between patients with VPI or not [10-12]. In this study, we included a large cohort to evaluate the predictive value of VPI on survival among node-negative invasive lung adenocarcinoma patients with tumor size less than $3 \mathrm{~cm}$. Our result helps with management of early stage NSCLC patients with VPI.

\section{RESULTS}

\section{Patient characteristics}

A total of 2537 patients were included in the cohort. Among them, there were 548 (21.6\%) with VPI, 1989 (78.4\%) without VPI. 1503 (59.2\%) patients were females and 1034 (40.8\%) patients were males. 1872 (73.8\%) patients less than or equal to 65 years old, $665(26.2 \%)$ patients older than 65 years old. Patients with tumor size less than or equal to $2 \mathrm{~cm}$ account for the majority (1559, $61.5 \%)$, there were $978(38.5 \%)$ patients with tumor size larger than $2 \mathrm{~cm}$ but less than or equal to $3 \mathrm{~cm}$. Only $146(5.8 \%)$ patients were detected with lymphovascular invasion. The number of patients with lepidic, acinar, papillary, micropapillary and solid were $226(8.9 \%)$, 1209(47.7\%), 1002(39.7\%), 13(0.5\%), 87(3.4\%) (Figure 1). The demographic features of 2537 patients were summarized in Table 1.

\section{Survival outcome}

The median follow-up survival was 37.3 (3.0-87.63) months. Among the 2537 patients, 2371 (93.5\%) were free of tumor recurrence and 166 (6.5\%) developed recurrence. A total of $80(3.2 \%)$ patients died during the follow-up period. First, we performed survival analysis in all 2537 patients. There were significant worse DFS and OS in patients with visceral pleural invasion (Figure 2).

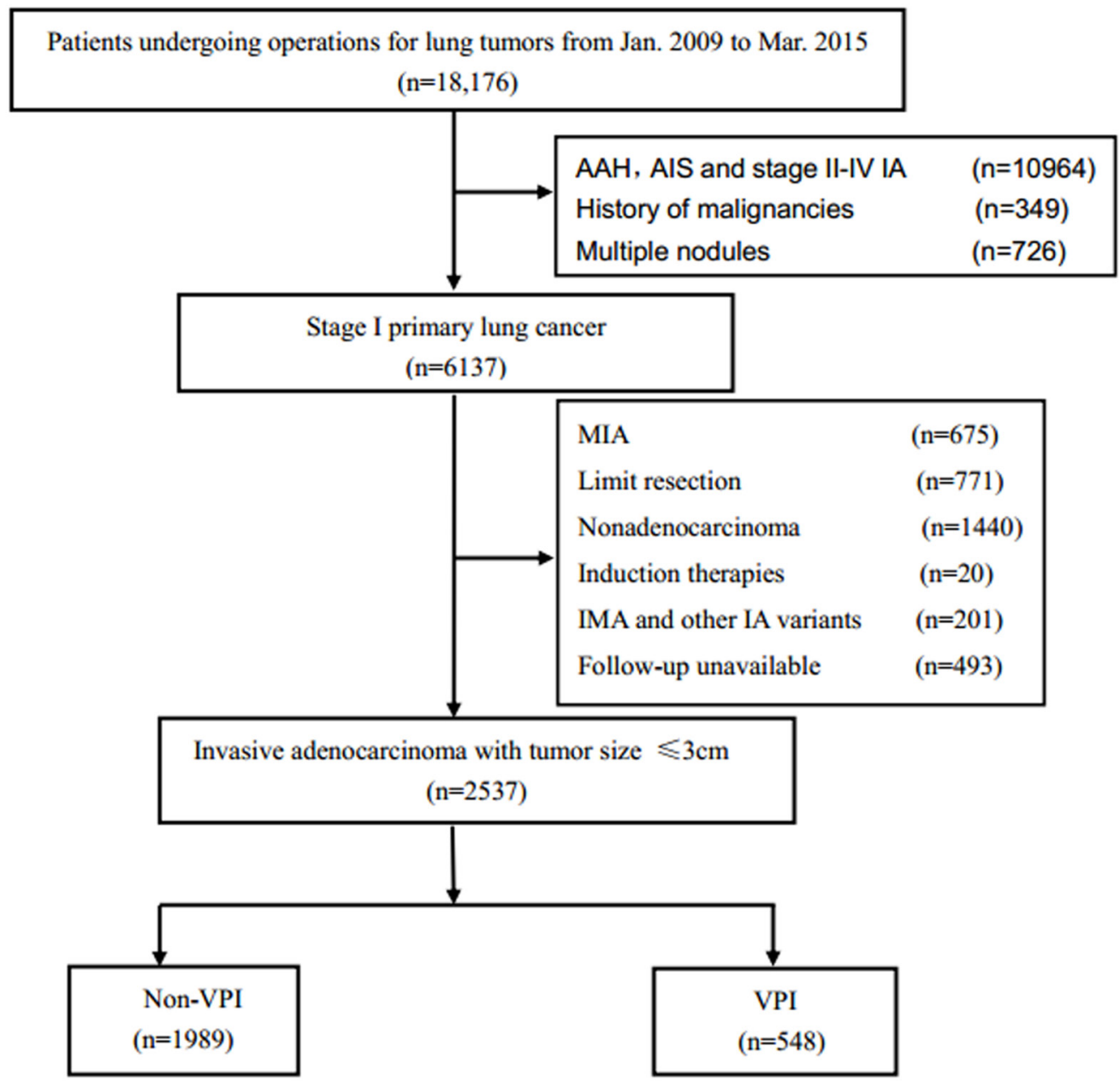

Figure 1: The selection process of eligible patients. Abbreviations: AAH=Atypical adenomatous hyperplasia; $A$ IS = adenocarcinoma in situ; MIA=microinvasive adenocarcinoma; IA=invasive adenocarcinoma; VPI= visceral pleural invasion 
Table 1: Baseline characteristics of patients with stage I lung adenocarcinoma

\begin{tabular}{|c|c|c|c|c|}
\hline Characteristic & $\begin{array}{c}\text { Total } \\
(N=) 2537\end{array}$ & $\begin{array}{l}\text { non-VPI } \\
(n=1989)\end{array}$ & $\begin{array}{c}\text { VPI } \\
(n=548)\end{array}$ & $p^{*}$ \\
\hline & No. & No. $\%$ & No. $\%$ & \\
\hline Sex & & & & .005 \\
\hline Male & $1034(40.8)$ & $782(39.3)$ & $252(46.0)$ & \\
\hline Female & $1503(59.2)$ & $1207(60.7)$ & $296(54.0)$ & \\
\hline Age, years & & & & .132 \\
\hline$\leq 65$ & $1872(73.8)$ & $1499(75.4)$ & $373(68.1)$ & \\
\hline$>65$ & $665(26.2)$ & $490(24.6)$ & $175(31.9)$ & \\
\hline Tumor size(cm) & & & & .000 \\
\hline$\leq 2$ & $1559(61.5)$ & $1335(67.1)$ & $224(40.9)$ & \\
\hline $2-3$ & $978(38.5)$ & $654(32.9)$ & $324(59.1)$ & \\
\hline Lymphovascular invasion & & & & .000 \\
\hline Yes & $146(5.8)$ & $85(4.3)$ & $61(11.1)$ & \\
\hline No & 2391(94.2) & $1904(95.7)$ & $487(88.9)$ & \\
\hline ACT & & & & .000 \\
\hline Yes & $500(19.7)$ & $209(10.5)$ & $291(53.1)$ & \\
\hline No & $2037(80.3)$ & $1780(89.5)$ & $257(46.9)$ & \\
\hline Adenocarcinoma subtype & & & & .000 \\
\hline Lepidic & $226(8.9)$ & $221(11.1)$ & $5(0.9)$ & \\
\hline Acinar & $1209(47.7)$ & $922(46.4)$ & $287(52.4)$ & \\
\hline Papillary & $1002(39.7)$ & $786(39.5)$ & $216(39.4)$ & \\
\hline Micropapillary & $13(0.5)$ & $8(0.4)$ & $5(0.9)$ & \\
\hline Solid & $87(3.4)$ & $52(2.6)$ & $35(6.4)$ & \\
\hline TNM & & & & .000 \\
\hline Ia1 & $291(11.5)$ & 291 & 0 & \\
\hline Ia2 & $1044(41.1)$ & 1044 & 0 & \\
\hline Ia3 & $654(25.4)$ & 654 & 0 & \\
\hline Ib & $548(21.6)$ & 0 & 548 & \\
\hline
\end{tabular}

Abbreviations: $\mathrm{ACT}=$ adjuvant chemotherapy; VPI=visceral pleural invasion

$* \chi^{2}$ test was calculated from logistic regression model stratified by trail. $P$ value is for the comparison between VPI and nonVPI.

In order to further evaluate the prognostic effect of VPI among patients with tumor size smaller than $3 \mathrm{~cm}$, we next divided patients into 4 groups based on tumor size and visceral pleural invasion status. Group 1, tumor size $\leq$ $2 \mathrm{~cm}$ and without VPI; group 2, tumor size $\leq 2 \mathrm{~cm}$ and with VPI; group 3 , tumor size $>2 \mathrm{~cm}$ but $\leq 3 \mathrm{~cm}$, without VPI; group 4 , tumor size $>2 \mathrm{~cm}$ and $\leq 3 \mathrm{~cm}$ and with VPI. The DFS and OS in each group were shown in Figure 3.

In tumor size $\leq 2 \mathrm{~cm}$ groups, patients with VPI had significant worse DFS(HR,4.85; 95\% CI, 2.98-7.91; $p$ $=.000)$ and OS(HR,3.52; 95\% CI, 1.59-7.78; $p=.002)$ compared with patients who had no VPI. In tumor size $2-3 \mathrm{~cm}$ groups, patients with VPI had significant worse DFS (HR, 1.72; 95\% CI, 1.16-2.55; $p=.006$ ), however, there were signifcant no difference for OS (HR, 1.31;
95\% CI, 0.76-2.24; $p=.330)$ compared with patients who had not VPI. For patients without VPI, tumor size was an independent predictive factor. Patients with tumor size $2-3 \mathrm{~cm}$ had significant worse DFS(HR,2.96; 95\% CI, $1.93-4.54 ; p=.000)$ and OS(HR,4.09; 95\% CI, 2.18-7.67; $p=.000)$ compared with patients with tumor size $\leq 2 \mathrm{~cm}$. However, at the presence of VPI, tumor size had no impact on survival. In patients with VPI group, there were no survival difference between tumor size $2-3 \mathrm{~cm}$ group and $\leq 2 \mathrm{~cm}$ group for both DFS(HR, 1.02; 95\% CI, 0.65-1.61; $p=.939)$ and $\mathrm{OS}(\mathrm{HR}, 1.45 ; 95 \% \mathrm{CI}, 0.71-2.97 ; p=.315)$.

Next, we performed multivariate analysis to determine independent prognostic and predictive factors for OS and DFS using Cox forward stepwise regression model. Sex, tumor size, histology subtype, LVI and VPI 
Table 2: Multivariate analysis of overall survival and disease free survival

\begin{tabular}{|l|c|c|c|c|c|c|}
\hline \multirow{2}{*}{\multicolumn{1}{|c|}{ Predictor }} & \multicolumn{3}{c|}{ DFS } & \multicolumn{3}{c|}{ OS } \\
\cline { 2 - 7 } & HR & $\mathbf{9 5 \%}$ CI & $\boldsymbol{P}$ & HR & $\mathbf{9 5 \% C I}$ & $\boldsymbol{P}$ \\
\hline Sex (male vs. female) & 1.61 & $1.18-2.19$ & .003. & 2.59 & $1.62-4.14$ & .000 \\
\hline Age (>60 vs. $\leq \mathbf{6 0})$ & 1.32 & $.97-1.80$ & .078 & 1.31 & $0.80-2.13$ & .268 \\
\hline Visceral pleural invasion (Yes vs. No) & 2.37 & $1.70-3.31$ & .000 & 1.67 & $1.03-2.71$ & .039 \\
\hline Lymphovascular invasion (Yes VS. No) & 2.33 & $1.53-3.56$ & .000 & 1.40 & $0.70-2.80$ & .338 \\
\hline ACT (Yes vs. No) & 0.93 & $0.65-1.34$ & .699 & 0.88 & $0.52-1.50$ & .643 \\
\hline Tumor size (2-3cm vs. $\leq \mathbf{2 c m )}$ & 1.64 & $1.19-2.28$ & .003 & 2.57 & $1.57-4.20$ & .000 \\
\hline Histology (SOL/MIP vs. LEP/ACN/PAP) & 2.19 & $1.32-3.62$ & .002 & .046 & $2.09-4.31$ & .052 \\
\hline
\end{tabular}

Abbreviations: $\mathrm{ACT}=$ adjuvant chemotherapy

were found as independent prognostic factors for DFS. Sex, VPI and tumor size were found as independent prognostic factors for OS (Table 2).

\section{DISCUSSION}

The adverse survival impact of VPI among early stage NSCLC patients remains controversial, especially in patients with tumor size less than $3 \mathrm{~cm}[7,13,14]$. This study, to our knowledge, collected the largest cohort for further evaluate the predictive value of VPI for postsurgical survival among lung invasive adenocarcinoma patients with tumor size less than or equal to $3 \mathrm{~cm}$. Our results indicated that, For patients with tumor size $\leq 3 \mathrm{~cm}$, VPI was a significant prognostic factor for poor survival regardless tumor size.

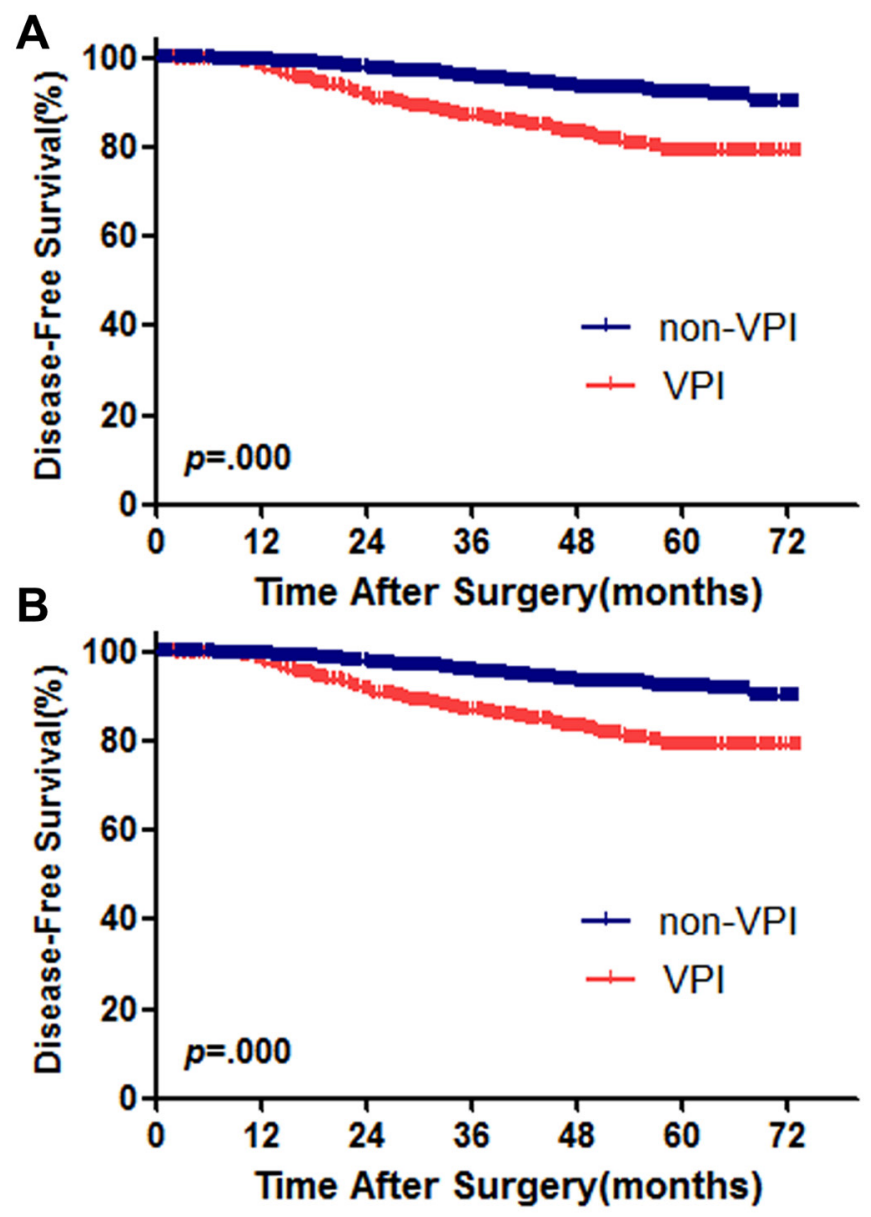

Figure 2: Survival cures for DFS (A) and OS (B) among patients with AIS, MIA and stage IA invasive adenocarcinoma. $p$ values from log-rank test. 
Although the $7^{\text {th }}$ TNM classification system had increased the $\mathrm{T}$ staging factor from $\mathrm{T} 1$ to $\mathrm{T} 2 \mathrm{a}$ and upstages a tumor from stage IA to stage IB, it is still controversial whether VPI reduces DFS and OS among patients with invasive tumor size less than $3 \mathrm{~cm}$. David and colleagues [10] indicated that VPI was not strongly related to DFS or OS for tumor size $<5 \mathrm{~cm}$. However, they did not present 5-year overall survival. A pool analysis [7] included more than 10 studies and examined the impact of VPI on 5-year OS with tumor size $\leq 3 \mathrm{~cm}$. The result demonstrated that patients with VPI had an unsatisfactory prognosis and regard VPI was an indicator of aggressive. Consistent with this pool analysis, our results showed that, among lymph node negative tumors $\leq 3 \mathrm{~cm}$, patients with VPI had a significantly worse survival in each tumor size group, and VPI was a major factor influencing survival rather than tumor size. A possible explanation for the results is visceral pleural is rich in lymphatic vessels, which eventually will join to the hilar lymph nodes [6, $15,16]$. As a consequence, VPI is associated with a higher frequency of locoregional recurrence and system metastasis. Post-surgical adjuvant chemotherapy may help to eliminate the residual cancer cells in the lymphatic vessel system. However, whether patients with VPI will benefit from adjuvant chemotherapy remains unclear. The current National Comprehensive Cancer Network (NCCN) guideline [17] suggests that patients with VPI should consider adjuvant chemotherapy. Unfortunately, this recommendation is lacking for high-level evidence support. Further clinical researches to figure the impact of adjuvant chemotherapy for VPI patients with tumor size $\leq 3 \mathrm{~cm}$ are warranted.
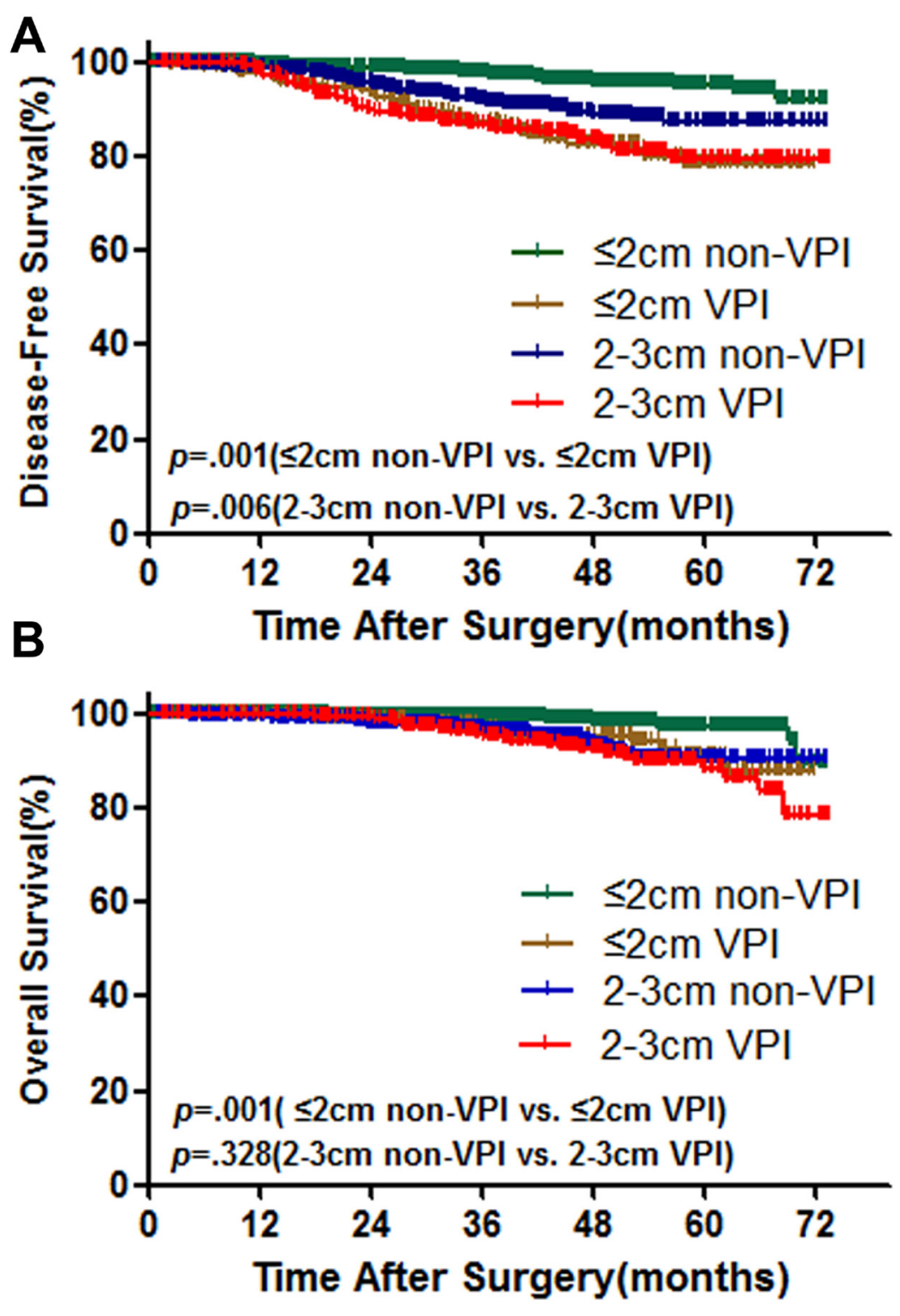

Figure 3: Survival cures for DFS (A) and OS (B) between patients with AIS/MIA and stage IA invasive adenocarcinoma. $p$ values from log-rank test. 
According to the current NCCN guideline, for early stage NSCLC patients, the optimal therapy strategy is curative-intent surgical lobectomy with mediastinal lymph node dissection or systematic sampling [18]. Our previous studies demonstrated that, for patients with tumor size less than $3 \mathrm{~cm}$-segmentectomy could achieve comparable outcomes with lobectomy, and wedge resection offer equal outcomes with lobectomy only in some specific histological predominant patterns. In order to reduce the selection bias, we only included patients who had received lobectomy and systemic lymph node dissection.

Some limitations of our research should be mentioned. First of all, this is a retrospective study, patient selection bias is inevitable. Even though our study included a large cohort, however, the results should be further validated by multicenter cohorts. Second, the postsurgical follow-up was insufficient which may affect the accuracy of survival results. Third, not all patients with VPI had received adjuvant chemotherapy, which may influence the patients' survival.

In conclusion, VPI is an aggressive prognostic factor for post-lobectomy survival for lymph node negative patients with tumor size less than $3 \mathrm{~cm}$. Our results are important for understanding biological behavior of VPI and help to guide the management of patients with VPI.

\section{MATERIALS AND METHODS}

\section{Patient cohort}

From January 2009 to March 2015, 18,176 consecutive patients with lung tumors undergoing resections in Shanghai Chest Hospital were identified. A total of 2537 patients with surgically resected pathologic N0 NSCLC with tumor size less than $3 \mathrm{~cm}$ in diameter were retrospectively reviewed. Correlative clinical data were retrieved from Shanghai Chest Hospital database. The study was approved by the Institutional Review Board of Shanghai Chest Hospital, Shanghai Jiao Tong University. All patients underwent complete resection of lung cancer. Inclusion criteria were invasive lung adenocarcinoma less than or equal to $3 \mathrm{~cm}$ with available hematoxylin and eosin (H\&E) slides for pathologic review. Exclusion criteria were adenocarcinoma in situ (AIS) and microinvasive adenocarcinoma (MIA), pathologic stage II disease and above, multicenter or metastatic disease, history of malignancy. Patients with invasion into the parietal pleura were excluded as well.

\section{Clinicopathological evaluation}

Hematoxylin and eosin -stained (H\&E) slides for each tumor were reviewed independently by two pathologists. The diagnosis of visceral pleural invasion is confirmed by elastic stain. The definition of visceral pleural invasion [19] is a tumor invades beyond the elastic layer with or without exposed on the pleural surface, but does not involve adjacent anatomic structures. Histopathologic criteria for AIS, MIA and invasive adenocarcinoma were according to the 2011 IASLC/ ATS/ERS classification [20]. Pathologic TNM Staging was based on the 7th edition of the American Committee on Cancer (AJCC) cancer staging manual [21]. The clinicopathologic features including sex, age, tumor size, surgical procedure, lymphovascular invasion (LVI) and survival status were collected from patients' medical records.

\section{Surveillance protocol}

Overall survival (OS) was calculated as the number of months from pulmonary resection until the date of death. Disease-free survival (DFS) was calculated as the number of months from pulmonary resection until the date of diagnosis of recurrence. DFS and OS status were obtained from clinical medical records or telephone follow-up.

The postoperative surveillance protocol was described as our previous publications [22-24]: physical examination, chest $\mathrm{CT}$, abdominal ultrasound examination was performed in every 6 months for the first year after surgery and at 6-month intervals thereafter. Wholebody bone scanning and brain magnetic resonance imaging (MRI) were performed once a year. Additional examinations were performed if patients had any symptoms occurred regardless of the follow-up schedule. For patients who did not follow-up in out hospital regularly, telephone follow-up were conducted to record the survival status.

\section{Statistical analysis}

The $\chi^{2}$ test for categorical variables was used to compare patients' characteristics between patients with VPI and without VPI. OS and DFS were estimated using the Kaplan-Meier method, and differences in survival were determined by log-rank analysis. Multivariable Cox regression analysis was used to assess the correlation of VPI with survival. Data were analyzed using Statistical Package for the Social Sciences Version 18.0 Software (SPSS Inc., Chicago, IL, USA). All $p$ values were twosided and $\mathrm{p}$ values less than 0.05 were considered statistically significant.

\section{CONFLICTS OF INTEREST}

The authors declare no conflicts of interest. 


\section{GRANT SUPPORT}

This article was supported by National Natural Science Foundation of China (81301996). The Ph.D Programs Foundation of Ministry of Education of China (20130101120017),Open Fund of Zhejiang Provincial Top Key Discipline of Pharmacology (YKFJ2-001), Medical Science and Technology of Heath of Zhejiang Provincial Government (2013KYA070).

\section{REFERENCES}

1. Zhu CQ, Ding K, Strumpf D, Weir BA, Meyerson M, Pennell N, Thomas RK, Naoki K, Ladd-Acosta C, Liu N, Pintilie M, Der S, Seymour L, et al. Prognostic and predictive gene signature for adjuvant chemotherapy in resected non-small-cell lung cancer. J Clin Oncol. 2010; 28: 4417-24.

2. Field JK, Smith RA, Aberle DR, Oudkerk M, Baldwin DR, Yankelevitz D, Pedersen JH, Swanson SJ, Travis WD, Wisbuba, II, Noguchi M, Mulshine JL, Participants ICSW. International Association for the Study of Lung Cancer Computed Tomography Screening Workshop 2011 report. J Thorac Oncol. 2012; 7: 10-9.

3. Wood DE, Eapen GA, Ettinger DS, Hou L, Jackman D, Kazerooni E, Klippenstein D, Lackner RP, Leard L, Leung AN, Massion PP, Meyers BF, Munden RF, et al. Lung cancer screening. J Natl Compr Canc Netw. 2012; 10: 24065.

4. Tsao MS, Marguet S, Le Teuff G, Lantuejoul S, Shepherd FA, Seymour L, Kratzke R, Graziano SL, Popper HH, Rosell R, Douillard JY, Le-Chevalier T, Pignon JP, et al. Subtype Classification of Lung Adenocarcinoma Predicts Benefit From Adjuvant Chemotherapy in Patients Undergoing Complete Resection. J Clin Oncol. 2015; 33: 3439-46.

5. Butnor KJ, Travis WD. Recent advances in our understanding of lung cancer visceral pleural invasion and other forms of minimal invasion: implications for the next TNM classification. Eur J Cardiothorac Surg. 2013; 43: 309-11.

6. Kudo Y, Saji H, Shimada Y, Nomura M, Matsubayashi J, Nagao T, Kakihana M, Usuda J, Kajiwara N, Ohira T, Ikeda N. Impact of visceral pleural invasion on the survival of patients with non-small cell lung cancer. Lung Cancer. 2012; 78: 153-60.

7. Jiang L, Liang W, Shen J, Chen X, Shi X, He J, Yang C, He J. The impact of visceral pleural invasion in node-negative non-small cell lung cancer: a systematic review and metaanalysis. Chest. 2015; 148: 903-11.

8. Rami-Porta R, Ball D, Crowley J, Giroux DJ, Jett J, Travis WD, Tsuboi M, Vallieres E, Goldstraw P, International Staging Committee, Cancer Research and Biostatistics, Observers to the Committee, Participating Institutions. The IASLC Lung Cancer Staging Project: proposals for the revision of the $\mathrm{T}$ descriptors in the forthcoming (seventh) edition of the TNM classification for lung cancer. J Thorac Oncol. 2007; 2: 593-602.

9. Groome PA, Bolejack V, Crowley JJ, Kennedy C, Krasnik M, Sobin LH, Goldstraw P, IASLC International Staging Committee, Cancer Research and Biostatistics, Observers to the Committee, Participating Institutions. The IASLC Lung Cancer Staging Project: validation of the proposals for revision of the $\mathrm{T}, \mathrm{N}$, and $\mathrm{M}$ descriptors and consequent stage groupings in the forthcoming (seventh) edition of the TNM classification of malignant tumours. J Thorac Oncol. 2007; 2: 694-705.

10. David E, Thall PF, Kalhor N, Hofstetter WL, Rice DC, Roth JA, Swisher SG, Walsh GL, Vaporciyan AA, Wei C, Mehran RJ. Visceral pleural invasion is not predictive of survival in patients with lung cancer and smaller tumor size. Ann Thorac Surg. 2013; 95: 1872-7.

11. Fan X, Zhang $X$, Wang $H$, Jin B. Reevaluation of survival and prognostic factors in pathologic stage I lung adenocarcinoma by the new 2009 TNM classification. Tumour Biol. 2014; 35: 5905-10.

12. Hattori A, Suzuki K, Matsunaga T, Takamochi K, Oh S. Visceral pleural invasion is not a significant prognostic factor in patients with a part-solid lung cancer. Ann Thorac Surg. 2014; 98: 433-8.

13. Huang H, Wang T, Hu B, Pan C. Visceral pleural invasion remains a size-independent prognostic factor in stage I nonsmall cell lung cancer. Ann Thorac Surg. 2015; 99: 1130-9.

14. Shimizu K, Yoshida J, Nagai K, Nishimura M, Ishii G, Morishita Y, Nishiwaki Y. Visceral pleural invasion is an invasive and aggressive indicator of non-small cell lung cancer. J Thorac Cardiovasc Surg. 2005; 130: 160-5.

15. Suzuki K, Nagai K, Yoshida J, Nishimura M, Nishiwaki Y. Predictors of lymph node and intrapulmonary metastasis in clinical stage IA non-small cell lung carcinoma. Ann Thorac Surg. 2001; 72: 352-6.

16. Fujimoto T, Cassivi SD, Yang P, Barnes SA, Nichols FC, Deschamps C, Allen MS, Pairolero PC. Completely resected N1 non-small cell lung cancer: factors affecting recurrence and long-term survival. J Thorac Cardiovasc Surg. 2006; 132: 499-506.

17. Ettinger DS, Wood DE, Akerley W, Bazhenova LA, Borghaei H, Camidge DR, Cheney RT, Chirieac LR, D’Amico TA, Demmy TL, Dilling TJ, Dobelbower MC, Govindan R, et al. Non-Small Cell Lung Cancer, Version 6.2015. J Natl Compr Canc Netw. 2015; 13: 515-24.

18. Wisnivesky JP, Henschke CI, Swanson S, Yankelevitz DF, Zulueta J, Marcus S, Halm EA. Limited resection for the treatment of patients with stage IA lung cancer. Ann Surg. 2010; 251: 550-4.

19. Travis WD, Brambilla E, Rami-Porta R, Vallieres E, Tsuboi M, Rusch V, Goldstraw P, International Staging C. Visceral pleural invasion: pathologic criteria and use of elastic stains: proposal for the 7th edition of the TNM classification for 
lung cancer. J Thorac Oncol. 2008; 3: 1384-90.

20. Travis WD, Brambilla E, Noguchi M, Nicholson AG, Geisinger KR, Yatabe Y, Beer DG, Powell CA, Riely GJ, Van Schil PE, Garg K, Austin JH, Asamura H, et al. International association for the study of lung cancer/ american thoracic society/european respiratory society international multidisciplinary classification of lung adenocarcinoma. J Thorac Oncol. 2011; 6: 244-85.

21. Goldstraw P, Crowley J, Chansky K, Giroux DJ, Groome PA, Rami-Porta R, Postmus PE, Rusch V, Sobin L, International Association for the Study of Lung Cancer International Staging C, Participating I. The IASLC Lung Cancer Staging Project: proposals for the revision of the TNM stage groupings in the forthcoming (seventh) edition of the TNM Classification of malignant tumours. J Thorac Oncol. 2007; 2: 706-14.

22. Luo J, Huang Q, Wang R, Han B, Zhang J, Zhao H, Fang W, Luo Q, Yang J, Yang Y, Zhu L, Chen T, Cheng X, et al. Prognostic and predictive value of the novel classification of lung adenocarcinoma in patients with stage IB. J Cancer Res Clin Oncol. 2016; 142: 2013-40.

23. Luo J, Wang R, Han B, Zhang J, Zhao H, Fang W, Luo Q, Yang J, Yang Y, Zhu L, Chen T, Cheng X, Huang Q, et al. Analysis of the clinicopathologic characteristics and prognostic of stage I invasive mucinous adenocarcinoma. J Cancer Res Clin Oncol. 2016; 142: 1837-45.

24. Luo J, Wang R, Han B, Zhang J, Zhao H, Fang W, Luo Q, Yang J, Yang Y, Zhu L, Chen T, Cheng X, Huang Q, et al. Solid predominant histologic subtype and early recurrence predict poor postrecurrence survival in patients with stage I lung adenocarcinoma. Oncotarget. 2017; 8: 7050-58. doi: 10.18632/oncotarget.12540. 